\title{
The rs1014290 Polymorphism of the SLC2A9 Gene Is Associated with Type 2 Diabetes Mellitus in Han Chinese
}

\author{
Wan-Chun Liu,, ${ }^{1,2}$ Chi-Chih Hung, ${ }^{2}$ Szu-Chia Chen,, 1 Ming-Yen Lin, ${ }^{2}$ \\ Ling-I Chen, ${ }^{2}$ Daw-Yang Hwang, ${ }^{2}$ Jer-Ming Chang, ${ }^{1,2,3}$ Jer-Chia Tsai, ${ }^{2,3}$ \\ Hung-Chun Chen, ${ }^{2,3}$ and Shang-Jyh Hwang ${ }^{2,3}$ \\ ${ }^{1}$ Department of Internal Medicine, Kaohsiung Municipal Hsiaokang Hospital, Kaohsiung, Taiwan \\ ${ }^{2}$ Division of Nephrology, Department of Internal Medicine, Kaohsiung Medical University, Chung-Ho Memorial Hospital, \\ 100 Tzyou First Road, Kaohsiung 807, Taiwan \\ ${ }^{3}$ Department of Internal Medicine, Faculty of Renal Care, College of Medicine, Kaohsiung Medical University, Kaohsiung, Taiwan
}

Correspondence should be addressed to Shang-Jyh Hwang, sjhwang@cc.kmu.edu.tw

Received 24 December 2010; Revised 22 February 2011; Accepted 23 February 2011

Academic Editor: Giuseppe Paolisso

Copyright (c) 2011 Wan-Chun Liu et al. This is an open access article distributed under the Creative Commons Attribution License, which permits unrestricted use, distribution, and reproduction in any medium, provided the original work is properly cited.

\begin{abstract}
Aims. The SLC2A9 gene encodes the glucose transporter 9, with the abilities of transporting both glucose and uric acid and is involved in the pancreatic glucose-stimulated insulin secretion. The single nucleotide polymorphisms (SNPs) of SLC2A9 accounted for $5 \%$ variance of serum uric acid (UA). UA was identified as a risk factor for type 2 diabetes mellitus (DM). We investigated whether the SLC2A9 gene variations are associated with type 2 DM in Han Chinese. Methods. Three common SNPs of the SLC2A9, rs1014290, rs2280205, and rs3733591, were genotyped in 1003 Han Chinese randomly selected from Kaohsiung, Taiwan. Results. The variant SNP rs1014290 is associated with decreased 0.12 -fold risk of type $2 \mathrm{DM}(P=.002)$. Per-copy increase in the minor Callele results in $0.13 \mathrm{mmol} / \mathrm{L}(P=.037)$ and $10.03 \mu \mathrm{mol} / \mathrm{L}(P=.016)$ decrease in serum glucose and UA, respectively. Conclusions. The SNP rs1014290 within the SLC2A9 gene is associated with type 2 DM in Han Chinese.
\end{abstract}

\section{Introduction}

Type 2 diabetes mellitus (DM), characterized by insulin resistance and relative insulin deficiency, is a complex disease with contributions from both genetic and environmental factors. Serum uric acid (UA) was associated with insulin resistance and also a risk factor for development of type 2 DM [1-5]. Meta-analysis showed that the pooled relative risk of a $1 \mathrm{mg} / \mathrm{dL}$ increase in UA was 1.17 for incident type 2 DM [5]. In the animal model, elevated UA level may worsen insulin resistance by inhibition of the bioavailability of nitric oxide, which is one of the essential components of insulin-stimulated glucose uptake [6]. The genetic influences outweighed the environmental factors in the estimation of serum UA by $63-73 \%[7,8]$, with total genetic variability accounted for $5 \%$ of UA variance [9]. The common variants of SLC2A9 gene have a significant role in the UA level, which accounted for $5-6 \%$ and $1-2 \%$ variables in the female and male, respectively.
The SLC2A9 gene encodes the solute carrier family 2, facilitated glucose transporter member 9 (GLUT9), initially identified by sequence similarity with members of the glucose transporter (Glut) family [10]. The function of GLUT9 is a high-capacity uric acid transporter in addition to a glucose transporter [11-14]. Furthermore, GLUT9 affected glucose-stimulated insulin secretion in the pancreatic $\beta$ cell and can be upregulated in the diabetic mouse $[15,16]$.

Due to the GLUT9's dual capabilities of uric acid and glucose transportations, we proposed that the SLC2A9 variations might be associated with type $2 \mathrm{DM}$. In this study, we investigated three common single nucleotide polymorphisms (SNP) of the SLC2A9 gene and their association with type $2 \mathrm{DM}$ in the Han Chinese.

\section{Method}

2.1. Study Participants. A cross-sectional survey was performed from one million population of Kaohsiung County, 
TABLE 1: Clinical characteristics stratified by sex and DM of enrolled subjects.

\begin{tabular}{|c|c|c|c|c|c|c|}
\hline \multirow{2}{*}{ Stratification } & \multicolumn{2}{|c|}{ Sex } & \multirow{2}{*}{$P$ value } & \multicolumn{2}{|c|}{$\mathrm{DM}$} & \multirow{2}{*}{$P$ value } \\
\hline & Male & Female & & Non-DM & $\mathrm{DM}$ & \\
\hline Subject No. & 484 & 519 & & 923 & 80 & \\
\hline Age (years) & $49.0 \pm 0.8$ & $47.6 \pm 0.7$ & .236 & $47.1 \pm 0.6$ & $62.5 \pm 1.3$ & $<.001$ \\
\hline Sex (male\%) & - & - & - & $48.6 \%$ & $43.8 \%$ & .245 \\
\hline BMI $\left(\mathrm{kg} / \mathrm{m}^{2}\right)$ & $24.7 \pm 0.2$ & $23.5 \pm 0.2$ & $<.001$ & $23.9 \pm 0.1$ & $25.3 \pm 0.6$ & .013 \\
\hline MBP (mmHg) & $98.5 \pm 1.0$ & $92.0 \pm 0.7$ & $<.001$ & $94.0 \pm 0.5$ & $107.9 \pm 4.3$ & .002 \\
\hline Glucose (mmol/L) & $4.85 \pm 0.07$ & $4.84 \pm 0.07$ & .985 & $4.55 \pm 0.02$ & $5.99 \pm 0.35$ & $<.001$ \\
\hline Uric Acid $(\mu \mathrm{mol} / \mathrm{L})$ & $410.4 \pm 6.0$ & $303.3 \pm 6.0$ & $<.001$ & $350.9 \pm 5.9$ & $380.7 \pm 11.9$ & .067 \\
\hline Hemoglobin $(\mathrm{g} / \mathrm{L})$ & $150.8 \pm 0.6$ & $132.3 \pm 0.6$ & $<.001$ & $141.1 \pm 0.5$ & $141.9 \pm 1.5$ & .678 \\
\hline Cholesterol (mmol/L) & $4.97 \pm 0.04$ & $5.08 \pm 0.04$ & .066 & $5.01 \pm 0.03$ & $5.25 \pm 0.12$ & .036 \\
\hline Triglyceride (mmol/L) & $1.55 \pm 0.06$ & $1.24 \pm 0.04$ & $<.001$ & $1.32 \pm 0.03$ & $2.21 \pm 0.18$ & $<.001$ \\
\hline $\mathrm{HDL}(\mathrm{mmol} / \mathrm{L})$ & $1.41 \pm 0.02$ & $1.68 \pm 0.02$ & $<.001$ & $1.57 \pm 0.01$ & $1.31 \pm 0.04$ & $<.001$ \\
\hline $\mathrm{LDL}(\mathrm{mmol} / \mathrm{L})$ & $3.14 \pm 0.04$ & $3.10 \pm 0.04$ & .513 & $3.10 \pm 0.03$ & $3.30 \pm 0.11$ & .048 \\
\hline eGFR (mL/s) & $1.38 \pm 0.02$ & $1.30 \pm 0.02$ & $<.001$ & $1.36 \pm 0.02$ & $1.08 \pm 0.05$ & $<.001$ \\
\hline Type 2 DM (\%) & $7.2 \%$ & $8.7 \%$ & .401 & - & - & - \\
\hline Hypertension (\%) & $17.9 \%$ & $14.7 \%$ & .169 & $14.0 \%$ & $42.5 \%$ & $<.001$ \\
\hline Metabolic syndrome (\%) & $10.1 \%$ & $11.8 \%$ & .235 & $7.5 \%$ & $51.3 \%$ & $<.001$ \\
\hline Cardiovascular disease (\%) & $4.8 \%$ & $5.4 \%$ & .382 & $4.9 \%$ & $7.5 \%$ & .219 \\
\hline Cerebrovascular disease (\%) & $1.5 \%$ & $0.8 \%$ & .233 & $1.0 \%$ & $2.5 \%$ & .219 \\
\hline Gout $(\%)$ & $10.4 \%$ & $2.1 \%$ & $<.001$ & $5.9 \%$ & $8.8 \%$ & .211 \\
\hline \multicolumn{7}{|l|}{ Minor allele frequency } \\
\hline rs 1014290 & $44.3 \%$ & $40.1 \%$ & .011 & $43.3 \%$ & $28.8 \%$ & $<.001$ \\
\hline rs2280205 & $22.5 \%$ & $23.0 \%$ & .576 & $22.5 \%$ & $25.0 \%$ & .266 \\
\hline rs3733591 & $34.6 \%$ & $33.6 \%$ & .245 & $33.5 \%$ & $40.6 \%$ & .179 \\
\hline
\end{tabular}

Values are expressed as mean \pm SEM or percentage.

The $P$ values were determined from $t$-tests for continuous variables and from Pearson chi-square test, and fisher's exact test for categorical variables. Abbreviations: BMI: body mass index, MBP: mean blood pressure, HDL: high-density lipoprotein, LDL: low-density lipoprotein, eGFR: estimated glomerular filatration rate, DM: diabetes mellitus.

Taiwan. Twelve villages were randomized selected from twenty-seven villages with a total of 1003 subjects sampled through multistage stratified approaches between April 2007 and January 2008. Height, body weight, abdominal girth, and blood pressure were measured at the screen day. All clinical information including underlying diseases, drug history, and social habits were accomplished by trained persons via a standard questionnaire according to the subject's statement. Aborigines and foreigners were excluded from this survey. The type 2 DM was diagnosed by the subject's statement and serum glucose above $7 \mathrm{mmol} / \mathrm{L}(126 \mathrm{mg} / \mathrm{dL})$.

2.2. Genotype Analysis. Three SNPs (rs2280205, rs1014290, and rs3733591) of the SLC2A9 gene were selected for genotype analysis with minor allele frequency $>20 \%$ in Han Chinese (according to HapMap data). These three SNPs were reported to be associated with uric-acid-related phenotypes, such as gout and tophus formation $[13,17]$. DNA was collected from the peripheral blood leukocytes and genotyping was performed by the TaqMan SNP allelic discrimination assay with an ABI 7900HT Sequence Detection System [18].

2.3. Statistical Analysis. The differences of clinical characteristics between sexes, diabetes, and genotypes were analyzed by Student's $t$-test, Pearson's Chi-square test, Fisher's exact test, and analysis of variance (ANOVA). The genotype and allele frequencies for Hardy-Weinberg equilibrium proportions were tested by Pearson's Chi-square test. Linear regression was used to investigate the changes in uric acid and serum glucose for per-copy increment in the minor allele. Binary logistic regression was used to evaluate the risk of type 2 DM between genotype groups. Statistical analyses were performed with SPSS version 18. $P$ values less than .05 were considered statistically significant. Subjects were analyzed by sex stratification to evaluate the gender influence of the SLC2A9 on type 2 DM, since the SLC2A9 has a female-predominant effect on UA level.

\section{Result}

The minor allele frequencies of the investigated SNPs were $42.1 \%$ for rs $1014290,22.7 \%$ for rs 2280205 , and $34.1 \%$ for rs3733591. These genotype frequencies were similar to the Han Chinese of the Hapmap database and all were in agreement with the Hardy-Weinberg equilibrium. All three loci are not in linkage. The demographic and clinical characteristics of study participants stratified by sex and DM were shown in Table 1. In the sex stratification, female had lower body mass index (BMI), mean arterial pressure (MBP), 
TABLE 2: Clinical characteristics stratified by rs $1014290 \mathrm{C} / \mathrm{T}$ polymorphism in both sex in the SLC2A9 gene.

\begin{tabular}{|c|c|c|c|c|c|c|c|c|}
\hline & \multicolumn{3}{|c|}{ Male } & \multirow{2}{*}{$P$ value } & \multicolumn{3}{|c|}{ Female } & \multirow{2}{*}{$P$ value } \\
\hline & TT & CT & CC & & TT & CT & CC & \\
\hline Subjects No. & 147 & 245 & 92 & & 177 & 268 & 74 & \\
\hline Age (years) & $49.9 \pm 1.5$ & $48.1 \pm 1.2$ & $48.1 \pm 1.9$ & .617 & $47.6 \pm 1.3$ & $47.6 \pm 1.0$ & $49.8 \pm 1.8$ & .582 \\
\hline BMI $\left(\mathrm{kg} / \mathrm{m}^{2}\right)$ & $24.8 \pm 0.3$ & $24.7 \pm 0.4$ & $24.2 \pm 0.4$ & .651 & $23.8 \pm 0.3$ & $23.5 \pm 0.3$ & $23.2 \pm 0.5$ & .625 \\
\hline MBP (mmHg) & $101.5 \pm 2.6$ & $97.7 \pm 0.9$ & $94.3 \pm 1.5$ & .032 & $92.8 \pm 1.1$ & $92.4 \pm 0.9$ & $90.6 \pm 1.6$ & .580 \\
\hline Glucose (mmol/L) & $4.92 \pm 0.14$ & $4.79 \pm 0.09$ & $4.64 \pm 0.07$ & .298 & $5.17 \pm 0.17$ & $4.78 \pm 0.07$ & $4.56 \pm 0.10$ & .006 \\
\hline Uric Acid $(\mu \mathrm{mol} / \mathrm{L})$ & $410.4 \pm 6.0$ & $410.4 \pm 6.0$ & $398.5 \pm 11.9$ & .575 & $321.2 \pm 6.0$ & $303.3 \pm 6.0$ & $279.6 \pm 6.0$ & .002 \\
\hline Hemoglobin $(\mathrm{g} / \mathrm{L})$ & $151.9 \pm 1.1$ & $150.8 \pm 0.8$ & $149.0 \pm 1.5$ & .269 & $133.4 \pm 1.0$ & $132.1 \pm 0.9$ & $130.2 \pm 1.7$ & .243 \\
\hline Cholesterol (mmol/L) & $5.01 \pm 0.07$ & $4.97 \pm 0.06$ & $4.89 \pm 0.12$ & .622 & $5.16 \pm 0.08$ & $5.03 \pm 0.06$ & $5.08 \pm 0.11$ & .405 \\
\hline Triglyceride (mmol/L) & $1.65 \pm 0.09$ & $1.46 \pm 0.06$ & $1.52 \pm 0.18$ & .306 & $1.32 \pm 0.07$ & $1.21 \pm 0.05$ & $1.32 \pm 0.16$ & .435 \\
\hline $\mathrm{HDL}(\mathrm{mmol} / \mathrm{L})$ & $1.40 \pm 0.03$ & $1.44 \pm 0.03$ & $1.44 \pm 0.04$ & .637 & $1.67 \pm 0.03$ & $1.66 \pm 0.03$ & $1.69 \pm 0.05$ & .830 \\
\hline $\mathrm{LDL}(\mathrm{mmol} / \mathrm{L})$ & $3.14 \pm 0.06$ & $3.15 \pm 0.06$ & $3.05 \pm 0.10$ & .630 & $3.17 \pm 0.07$ & $3.08 \pm 0.05$ & $3.06 \pm 0.09$ & .517 \\
\hline eGFR (mL/s) & $1.38 \pm 0.04$ & $1.40 \pm 0.03$ & $1.39 \pm 0.05$ & .858 & $1.32 \pm 0.03$ & $1.28 \pm 0.02$ & $1.23 \pm 0.04$ & .201 \\
\hline Type 2 DM (\%) & $9.5 \%$ & $8.2 \%$ & $1.1 \%$ & .036 & $13.0 \%$ & $7.5 \%$ & $2.7 \%$ & .018 \\
\hline Hypertension (\%) & $19.0 \%$ & $17.2 \%$ & $18.0 \%$ & .900 & $16.4 \%$ & $14.3 \%$ & $12.2 \%$ & .655 \\
\hline Metabolic syndrome (\%) & $11.6 \%$ & $10.2 \%$ & $7.6 \%$ & .614 & $13.0 \%$ & $12.3 \%$ & $6.8 \%$ & .346 \\
\hline Cardiovascular disease (\%) & $4.8 \%$ & $4.1 \%$ & $6.7 \%$ & .607 & $5.7 \%$ & $4.9 \%$ & $6.8 \%$ & .809 \\
\hline Cerebrovascular disease (\%) & $2.0 \%$ & $1.2 \%$ & $1.1 \%$ & .777 & $1.1 \%$ & $0.8 \%$ & $0.0 \%$ & .647 \\
\hline Gout $(\%)$ & $15.1 \%$ & $8.2 \%$ & $9.0 \%$ & .088 & $3.4 \%$ & $1.5 \%$ & $1.4 \%$ & .356 \\
\hline
\end{tabular}

Values are expressed as mean \pm SEM or percentage.

The $P$ values were determined from $t$-tests for continuous variables and from Pearson chi square test and fisher's exact test for categorical variables. Abbreviations: as Table 1.

uric acid, hemoglobin, triglyceride, estimated glomerular filtration rate (eGFR), and percentage of gout but higher high-density lipoprotein (HDL). In the DM stratification, the DM subgroup was older and has higher BMI, MBP, fasting serum glucose, uric acid, cholesterol, triglyceride, low-density lipoprotein (LDL), and higher percentages of hypertension and metabolic syndrome but lower HDL and eGFR than non-DM subgroup. The genotype frequencies of the SNP rs1014290 were lower in the female and the DM subgroup.

3.1. Genotype Analysis of Investigated SNPs. The rs 1014290 showed different frequencies of type $2 \mathrm{DM}$ between genotype groups (Table 2$)$. Lower glucose $(P=.006)$, uric acid $(P=$ $.002)$, and type $2 \mathrm{DM}(P=.019)$ were found to be associated with the rs 1014290 only in the female but not in the male. There were no differences in the other clinical characteristics between genotype groups.

In all subjects, each copy of SNP rs1014290 minor Callele decreased covariate adjusted glucose and uric acid level by $0.13 \mathrm{mmol} / \mathrm{L}(P=.037)$ and $10.03 \mu \mathrm{mol} / \mathrm{L}(P=$ $.006)$, respectively. In female subgroup, the decreased effect of minor C-allele on glucose and uric acid level was more predominant. Each copy increase of the minor Callele resulted in $0.22 \mathrm{mmol} / \mathrm{L}$ decrease $(P=.018)$ and $18.39 \mu \mathrm{mol} / \mathrm{L}$ decrease $(P<.001)$ in covariate adjusted glucose level and uric acid level, respectively. The significant effect of SNP rs1014290 on glucose and uric acid level decrease was not replicated in male participants (Table 3).
TABle 3: Glucose and uric acid level differences for per-copy increase of minor allele for rs1014290 in the SLC2A9 gene.

\begin{tabular}{|c|c|c|c|c|}
\hline & \multicolumn{2}{|c|}{ Glucose } & \multicolumn{2}{|c|}{ Uric Acid } \\
\hline & $\begin{array}{l}\text { Unstandardized } \\
\text { coefficient } \beta\end{array}$ & $P$ value & $\begin{array}{l}\text { Unstandardized } \\
\text { coefficient } \beta\end{array}$ & $P$ value \\
\hline \multicolumn{5}{|l|}{ Total } \\
\hline Unadjusted & -0.24 & .001 & -8.17 & .080 \\
\hline Adjusted & -0.13 & .037 & -10.03 & .006 \\
\hline \multicolumn{5}{|l|}{ Male } \\
\hline Unadjusted & -0.13 & .156 & -5.05 & .391 \\
\hline Adjusted & -0.03 & .759 & -2.35 & .676 \\
\hline \multicolumn{5}{|l|}{ Female } \\
\hline Unadjusted & -0.34 & .002 & -19.35 & $<.001$ \\
\hline Adjusted & -0.22 & .018 & -18.39 & $<.001$ \\
\hline \multicolumn{5}{|c|}{$\begin{array}{l}\text { Values are expressed as unstandardized coefficient. } \\
\text { The } P \text { values were determined from linear regression analysis. } \\
\text { Adjusted for age, eGFR, MBP, cholesterol, triglyceride, HDL, BMI, antidi- } \\
\text { abetic agents and sex in total group (sex was excluded in sex subgroup } \\
\text { analysis) in glucose analysis. }\end{array}$} \\
\hline
\end{tabular}

In all subjects, each copy of SNP rs1014290 minor Callele decreased covariate adjusted glucose and uric acid level by $0.13 \mathrm{mmol} / \mathrm{L}(P=.037)$ and $10.03 \mu \mathrm{mol} / \mathrm{L}(P=$ $.006)$, respectively. In the female subgroup, this effect was more predominant with $0.22 \mathrm{mmol} / \mathrm{L}$ decrease $(P=.018)$ and $18.39 \mu \mathrm{mol} / \mathrm{L}$ decrease $(P<.001)$ in covariate adjusted glucose level and uric acid level, respectively. This effect of 
TABLE 4: Binary logistic regression analysis for type 2 DM risk.

\begin{tabular}{|c|c|c|c|c|c|c|}
\hline & \multicolumn{2}{|c|}{ Unadjusted } & \multicolumn{2}{|c|}{ Adjusted model 1} & \multicolumn{2}{|c|}{ Adjusted model 2} \\
\hline & OR $(95 \% \mathrm{CI})$ & $P$ & OR $(95 \% \mathrm{CI})$ & $P$ & OR $(95 \% \mathrm{CI})$ & $P$ \\
\hline \multicolumn{7}{|l|}{ Total } \\
\hline \multicolumn{7}{|c|}{ rs1014290 variation } \\
\hline TT & 1 (Reference) & - & 1 (Reference) & - & 1 (Reference) & - \\
\hline $\mathrm{CT}$ & $0.63(0.39-1.01)$ & .056 & $0.66(0.40-1.09)$ & .101 & $0.67(0.39-1.13)$ & .136 \\
\hline $\mathrm{CC}$ & $0.15(0.05-0.49)$ & .002 & $0.15(0.05-0.51)$ & .002 & $0.12(0.03-0.45)$ & .002 \\
\hline Uric acid & $1.02(1.00-1.05)$ & .036 & $1.01(0.98-1.04)$ & .389 & $0.99(0.96-1.02)$ & .610 \\
\hline \multicolumn{7}{|l|}{ Male } \\
\hline \multicolumn{7}{|c|}{ rs1014290 variation } \\
\hline TT & 1 (Reference) & - & 1 (Reference) & - & 1 (Reference) & - \\
\hline $\mathrm{CT}$ & $0.81(0.39-1.67)$ & .564 & $0.85(0.40-1.79)$ & .672 & $0.86(0.37-1.97)$ & .719 \\
\hline $\mathrm{CC}$ & $0.11(0.01-0.86)$ & .036 & $0.12(0.02-0.94)$ & .043 & $0.09(0.01-0.93)$ & .043 \\
\hline Uric acid & $1.01(0.97-1.05)$ & .651 & $1.00(0.96-1.04)$ & .944 & $0.98(0.94-1.03)$ & .398 \\
\hline \multicolumn{7}{|l|}{ Female } \\
\hline \multicolumn{7}{|c|}{ rs1014290 variation } \\
\hline TT & 1 (Reference) & - & 1 (Reference) & - & 1 (Reference) & - \\
\hline CT & $0.52(0.27-0.98)$ & .044 & $0.53(0.26-1.05)$ & .069 & $0.50(0.24-1.05)$ & .066 \\
\hline $\mathrm{CC}$ & $0.19(0.04-0.81)$ & .025 & $0.17(0.04-0.76)$ & .021 & $0.13(0.02-0.70)$ & .018 \\
\hline Uric acid & $1.06(1.02-1.09)$ & .001 & $1.01(0.97-1.05)$ & .533 & $0.99(0.95-1.05)$ & .724 \\
\hline
\end{tabular}

Values are expressed as odds ratio (95\% confidence interval). For uric acid, odds ratio was expressed for per $10 \mu \mathrm{mol} / \mathrm{L}$ increase in level.

The $P$ values were determined from binary logistic regression analysis.

Model 1: adjusted for age, BMI, uric acid, the rs1014290 C/T polymorphism of SLC2A9 gene, and sex in total group (sex was excluded in sex subgroup analysis). Model 2: adjusted for covariates of model 1, MBP, cholesterol, HDL, LDL, and triglyceride.

Abbreviations: as Table 1.

SNP rs1014290 on glucose and uric acid level decrease was not found in the male participants (Table 3 ).

For all subjects and sex subgroup, the CC group of SLC2A9 SNP rs1014290 is associated with decreased risk for prevalent type $2 \mathrm{DM}$ either in unadjusted or in adjusted model (Table 4). In the total group, compared with the TT group, the CC group conferred covariate adjusted 0.12-fold decreased risk of prevalent type 2 DM (95\% confidence interval $(\mathrm{CI})=0.03-0.45, P=.002)$. In the subgroup analysis, this effect still existed in both sexes with weaker association in the male than in the female (male: odds ratio $(\mathrm{OR})=0.09,95 \% \mathrm{CI}=0.01-0.93, P=.043$; female: $\mathrm{OR}$ $=0.13,95 \% \mathrm{CI}=0.02-0.70, P=.018)$. In contrary to the rs1014290 polymorphism, the uric acid only exerts a significant effect on the prevalent type $2 \mathrm{DM}$ in unadjusted model of total and female group (OR for $10 \mu \mathrm{mol} / \mathrm{L}$ increase in UA level $=1.02,95 \% \mathrm{CI}=1.00-1.05, P=.036$; OR for $10 \mu \mathrm{mol} / \mathrm{L}$ increase in UA level $=1.06,95 \% \mathrm{CI}=1.02-1.09$, $P<.001$, resp.). The significant results of the rs 1014290 polymorphism on the prevalent type $2 \mathrm{DM}$ in the adjusted model suggested that the association between type $2 \mathrm{DM}$ and SLC2A9 variation is independent from the uric acid effect.

In the remaining variants of rs2280205 and rs3733591, no significant effects on the glucose, UA, and type 2 DM were found (Data not shown).

\section{Discussion}

We showed that in Han Chinese, the SLC2A9 SNP rs1014290 is relevant to the prevalent of type $2 \mathrm{DM}$ and serum glucose level in addition to the uric acid level. SNP rs1014290 variation is a nucleotide transversion from $\mathrm{T}$ to $\mathrm{C}$ located in the intron 3 of SLC2A9 gene. Its minor allele frequency in Asian is about 40\%, which is higher than the $30 \%$ in Caucasian according to HapMap data. The minor C-allele of SNP rs1014290 was found to associate with lower UA level, higher fractional excretion of uric acid and lower risks for gout and nephrolithiasis [13, 19]. The effect on decreasing uric acid level of minor C-allele of SNP rs1014290 is greater in female than in male. The influence of the SLC2A9 variation on glucose level is more predominant in the female, as well as uric acid showed in our study and previous reports [11-14]. In the total group, this female predominant effect on uric acid is powerful enough to make the insignificant unadjusted $P$ value become significant in adjusted model. The $P$ value changed from .075 to .002 when sex was added as covariate to the unadjusted model. In the Caucasian, the per copy of minor C-allele contributes to $45.2-50.6 \mu \mathrm{mol} / \mathrm{L}$ $(0.76-0.85 \mathrm{mg} / \mathrm{dL})$ decrease of serum uric acid level in the female and $10.1-21.4 \mu \mathrm{mol} / \mathrm{L}(0.17-0.36 \mathrm{mg} / \mathrm{dL})$ decrease in the male [13]. The effect of minor C-allele on decreasing uric acid level seems to be weaker in Han Chinese. 
In our study, each copy of minor C-allele decreases uric acid by $19.35 \mu \mathrm{mol} / \mathrm{L}$ and $5.05 \mu \mathrm{mol} / \mathrm{L}$ in female and in male, respectively, and this effect is insignificant in male. Similar result was found in a recent study including 191 male Han Chinese from Taiwan, where no influences of SNP rs1014290 variation on uric acid level were found [17]. Our data suggested that the SNP rs1014290 variation in the SLC2A9 is associated with serum uric acid level in the Han Chinese with female predominance.

GLUT9 was classified as glucose and/or fructose transporter despite very low transport activities [20, 21]. Recently, the GLUT9 was considered as a uric acid transporter rather than glucose and/or fructose transporter [11-14]. However, our study showed that the SNP rs1014290 variation is associated with type $2 \mathrm{DM}$ and serum glucose level (Tables 3 and 4). GLUT9 was found to be upregulated in liver and kidney tissue in diabetic mouse and affected the glucosesensing insulin secretion in pancreatic $\beta$ cell $[15,16]$. Pancreatic $\beta$ cell was responsible for detecting the change of blood glucose concentration and modulating insulin secretion, which consisted of a rapid first phase and the prolonged second phase. The first step for the pancreatic $\beta$ cell to sense extracellular glucose concentration is the uptake of glucose by glucose transporter. GLUT9 might be responsible for this glucose uptake in the prolonged second phase of insulin secretion. [15] Thus, the minor C-allele of SNP rs1014290 might exert an influence on the second phase of insulin secretion and consequently altered serum glucose level and type 2 DM development. In our result, the association between SNP rs1014290 variation and the prevalence of type $2 \mathrm{DM}$ is independent from the effect of uric acid.

Uric acid was identified as a risk factor for the development of type $2 \mathrm{DM}$ in other studies [1-5]. But our result was only significant in unadjusted model of total and female groups (Table 4). This might be due to the older age of our DM subjects than that of other study subjects. The mean age of our DM subjects is around 62.5 years which is older than other study subjects (around 40-60 years) [5]. This suggested that the age per se and the duration of DM might affect the association between UA and type 2 DM.

The minor allele frequency of SNP rs2280205 and SNP rs3733591 in our study is similar with that reported in Han Chinese group in HapMap data. The association between uric acid level and variations of SNP rs2280205 and SNP rs3733591 were reported [11], but the result was not replicated in our Han Chinese subjects. This may be due to the minor allele frequencies of SNP rs2280205 and SNP rs3733591 which are different between European and Han Chinese.

The limitations of this are that our study is lacking the accurate diagnosis of type $2 \mathrm{DM}$ and only random glucose level was tested without the measurement of glycosylated hemoglobin. This might lead to the finding that the SNP rs1014290 variation is not associated with serum glucose level but associated with type $2 \mathrm{DM}$ in the male group. This contradictory result could also derive from the confounding effect of antidiabetic agents use and the inconsistent treatment response to DM medication. All these could confound the interpretation of the genetic effects on type 2 DM risk.

In conclusion, the SNP rs1014290 variation of SLC2A9 gene was associated with type $2 \mathrm{DM}$ and serum glucose level in addition to uric acid level. The genetic effect on the association with type $2 \mathrm{DM}$ is independent from the uric acid effect. This suggested that the SLC2A9 gene may be a candidate genetic locus for the pathogenesis of type 2 DM.

\section{Acknowledgment}

Kaohsiung county survey program was supported by a Grant from the Bureau of Health Promotion, Department of Health, Executive Yuan, Taiwan, (DOH-96-HP-1102). The authors would like to thank Hui-Yen Yu for handling all details of survey procedure, Ming Yen Lin for performing sampling approaches, and all persons for assisting in coordinating and collecting data in this survey program. W.-C. Liu and C.-C. Hung contributed equally to this paper.

\section{References}

[1] A. Dehghan, M. van Hoek, E. J. G. Sijbrands, A. Hofman, and J. C. M. Witteman, "High serum uric acid as a novel risk factor for type 2 diabetes," Diabetes Care, vol. 31, no. 2, pp. 361-362, 2008.

[2] N. Nakanishi, M. Okamoto, H. Yoshida, Y. Matsuo, K. Suzuki, and K. Tatara, "Serum uric acid and risk for development of hypertension and impaired fasting glucose or Type II diabetes in Japanese male office workers," European Journal of Epidemiology, vol. 18, no. 6, pp. 523-530, 2003.

[3] K. L. Chien, M. F. Chen, H. C. Hsu et al., "Plasma uric acid and the risk of type 2 diabetes in a Chinese community," Clinical Chemistry, vol. 54, no. 2, pp. 310-316, 2008.

[4] M. R. Carnethon, S. P. Fortmann, L. Palaniappan, B. B. Duncan, M. I. Schmidt, and L. E. Chambless, "Risk factors for progression to incident hyperinsulinemia: the atherosclerosis risk in communities study, 1987-1998," American Journal of Epidemiology, vol. 158, no. 11, pp. 1058-1067, 2003.

[5] S. Kodama, K. Saito, Y. Yachi et al., "Association between serum uric acid and development of type 2 diabetes," Diabetes Care, vol. 32, no. 9, pp. 1737-1742, 2009.

[6] U. M. Khosla, S. Zharikov, J. L. Finch et al., "Hyperuricemia induces endothelial dysfunction," Kidney International, vol. 67, no. 5, pp. 1739-1742, 2005.

[7] Q. Yang, C. Y. Guo, L. A. Cupples, D. Levy, P. W. F. Wilson, and C. S. Fox, "Genome-wide search for genes affecting serum uric acid levels: the Framingham Heart Study," Metabolism, vol. 54, no. 11, pp. 1435-1441, 2005.

[8] J. B. Whitfield and N. G. Martin, "Inheritance and alcohol as factors influencing plasma uric acid levels," Acta Geneticae Medicae et Gemellologiae, vol. 32, no. 2, pp. 117-126, 1983.

[9] M. Kolz, T. Johnson, S. Sanna et al., "Meta-analysis of 28,141 individuals identifies common variants within five new loci that influence uric acid concentrations," PLoS Genetics, vol. 5, no. 6, article e1000504, 2009.

[10] J. E. Phay, H. B. Hussain, and J. F. Moley, "Cloning and expression analysis of a novel member of the facilitative glucose transporter family, SLC2A9 (GLUT9)," Genomics, vol. 66, no. 2, pp. 217-220, 2000. 
[11] A. Döring, C. Gieger, D. Mehta et al., "SLC2A9 influences uric acid concentrations with pronounced sex-specific effects," Nature Genetics, vol. 40, no. 4, pp. 430-436, 2008.

[12] S. Li, S. Sanna, A. Maschio et al., "The GLUT9 gene is associated with serum uric acid levels in Sardinia and Chianti cohorts.," PLoS genetics, vol. 3, no. 11, article e194, 2007.

[13] V. Vitart, I. Rudan, C. Hayward et al., "SLC2A9 is a newly identified urate transporter influencing serum urate concentration, urate excretion and gout," Nature Genetics, vol. 40, no. 4, pp. 437-442, 2008.

[14] C. Wallace, S. J. Newhouse, P. Braund et al., "Genome-wide association study identifies genes for biomarkers of cardiovascular disease: serum urate and dyslipidemia," American Journal of Human Genetics, vol. 82, no. 1, pp. 139-149, 2008.

[15] S. A. Evans, M. Doblado, M. M. Chi, J. A. Corbett, and K. H. Moley, "Facilitative glucose transporter 9 expression affects glucose sensing in pancreatic $\beta$-cells," Endocrinology, vol. 150, no. 12, pp. 5302-5310, 2009.

[16] C. Keembiyehetty, R. Augustin, M. O. Carayannopoulos et al., "Mouse glucose transporter 9 splice variants are expressed in adult liver and kidney and are up-regulated in diabetes," Molecular Endocrinology, vol. 20, no. 3, pp. 686-697, 2006.

[17] H. P. Tu, C. J. Chen, S. Tovosia et al., "Associations of a nonsynonymous variant in SLC2A9 with gouty arthritis and uric acid levels in Han Chinese subjects and Solomon Islanders," Annals of the Rheumatic Diseases, vol. 69, no. 5, pp. 887-890, 2010.

[18] Applied Biosystems, 850 Lincoln Centre Drive, Foster City, CA 94404, USA.

[19] O. Polasek, G. Gunjaca, I. Kolcić et al., "Association of nephrolithiasis and gene for glucose transporter type 9 (SLC2A9): study of 145 patients," Croatian Medical Journal, vol. 51, no. 1, pp. 48-53, 2010.

[20] S. Bibert, S. K. Hess, D. Firsov et al., "Mouse GLUT9: evidences for a urate uniporter," American Journal of Physiology, vol. 297, no. 3, pp. F612-F619, 2009.

[21] N. Anzai, K. Ichida, P. Jutabha et al., "Plasma urate level is directly regulated by a voltage-driven urate efflux transporter URATv1 (SLC2A9) in humans," Journal of Biological Chemistry, vol. 283, no. 40, pp. 26834-26838, 2008. 


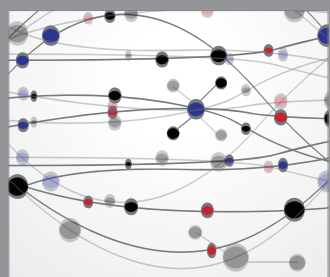

The Scientific World Journal
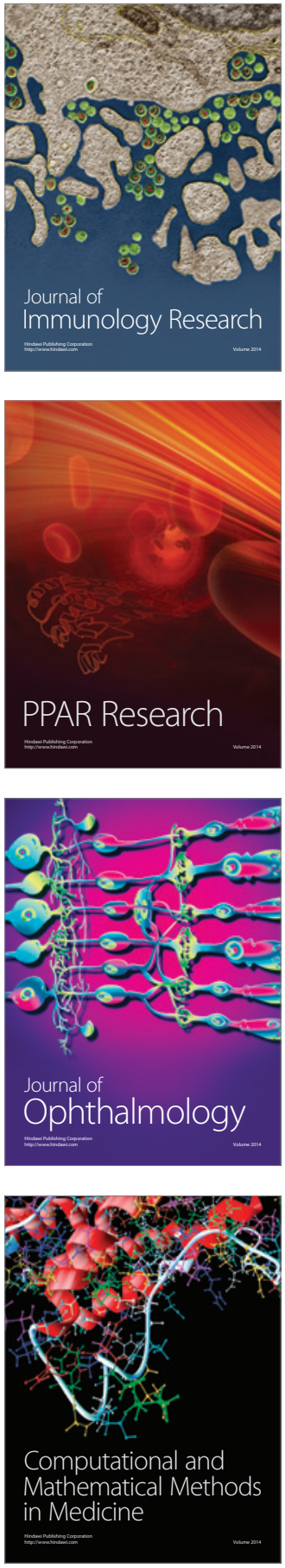

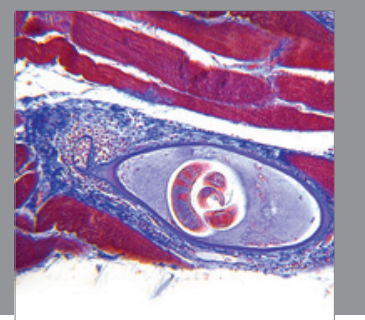

Gastroenterology

Research and Practice
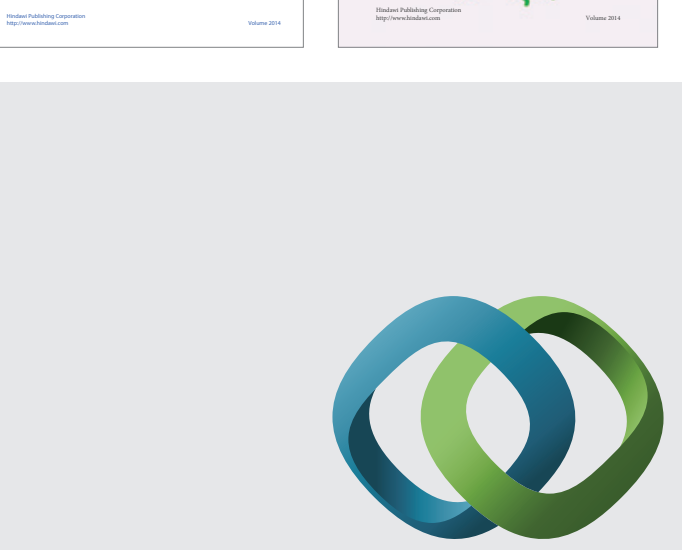

\section{Hindawi}

Submit your manuscripts at

http://www.hindawi.com
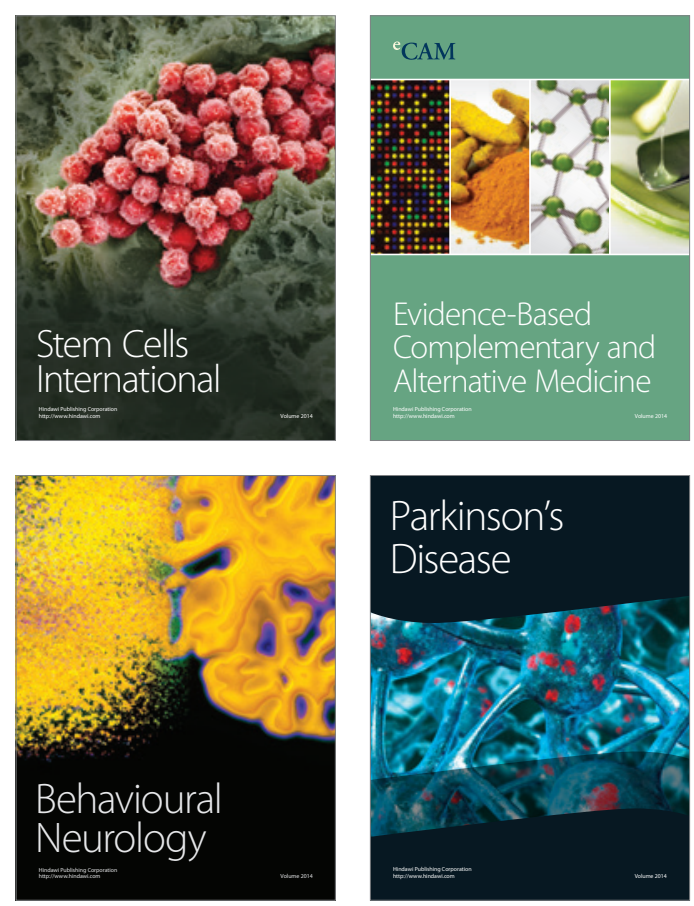

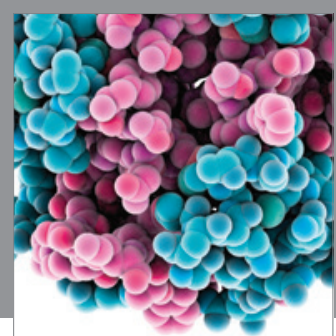

Journal of
Diabetes Research

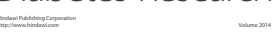

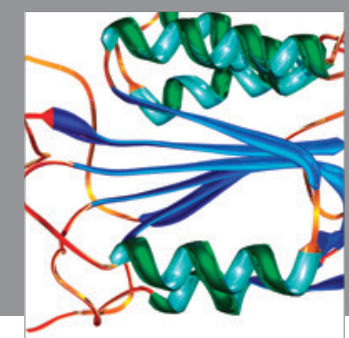

Disease Markers
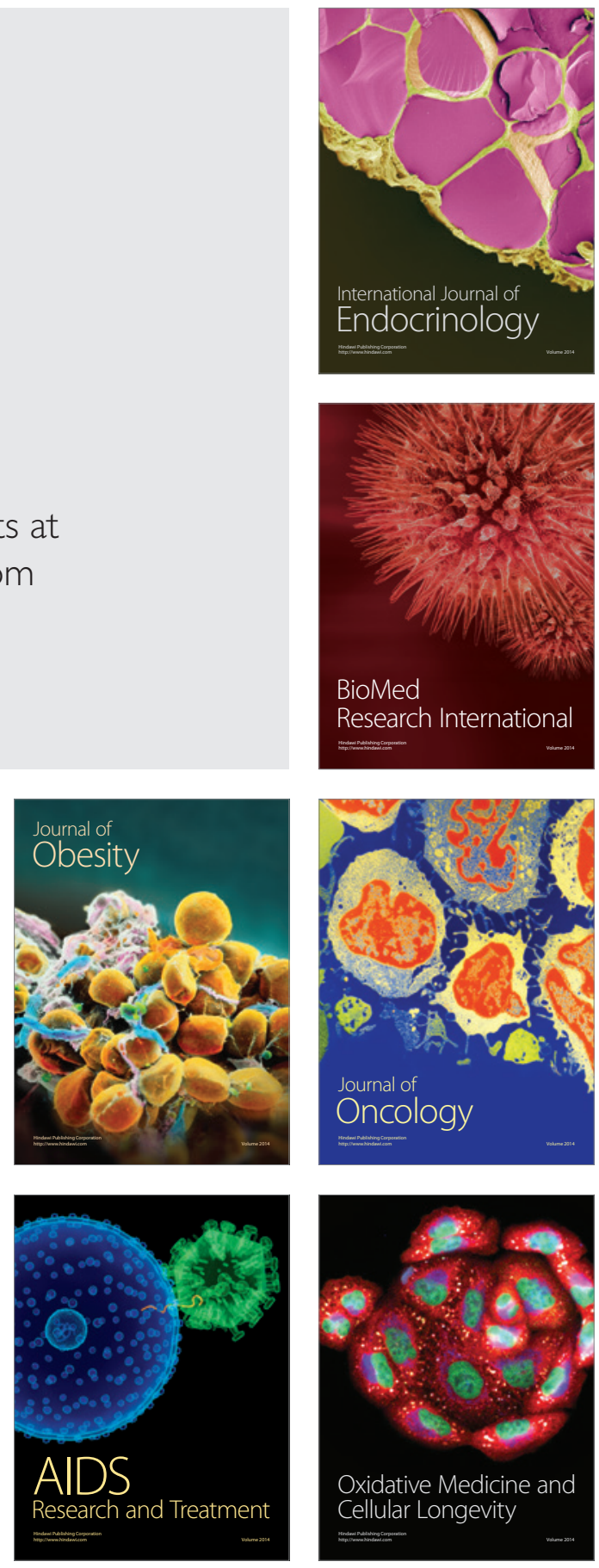